\title{
Correction
}

\section{Correction to: Probable intensity of Sylhet city from an event like 1918 Srimangal earthquake}

\author{
Sudipto Kumar Das ${ }^{1}$. Md. Nazmul Hasan ${ }^{1}$ - Md. Jahir Bin Alam ${ }^{1}$. Sourav Ray ${ }^{1}$
}

Published online: 14 May 2020

(c) Springer Nature Switzerland AG 2020

\section{Correction to: SN Applied Sciences (2019) 1:1630 https://doi.org/10.1007/s42452-019-1679-6}

Due to a misunderstanding, author Sourav Ray was not included in the original article.

Publisher's Note Springer Nature remains neutral with regard to jurisdictional claims in published maps and institutional affiliations.

The original article can be found online at https://doi.org/10.1007/s42452-019-1679-6.

$\triangle$ Sudipto Kumar Das, sudipto9747@gmail.com; surjo9747@student.sust.edu|'Department of Civil and Environmental Engineering, Shahjalal University of Science and Technology, Sylhet 3114, Bangladesh. 